\title{
Translating Memory Through Fashion
}

\author{
Kathryn Franklin \\ York University, Canada
}

Clothes found hanging in a closet comprise an archive of personal memories translated through the medium of fashion. Regardless of whether this archive is made up of couture dresses or faded sweatshirts each article of clothing is imbued with personal history. A certain cocktail dress may recall a particularly fun birthday party or a ragged university sweatshirt may conjure up memories of being a student studying for exams. Joanne Entwistle declares that "Dress, [...]. forms part of our epidermis - it lies on the boundary between self and other" (2001, 93). I would extend this metaphor further and argue that dress forms not only part of our epidermis but our subconscious as well.

Elizabeth Wilson pointedly contends that "Fashion, for all its hype, is also quintessentially about the everyday; everyday life. Clothes are what we put on every day; even those who most strenuously insist that what they wear has nothing to do with fashion and that they are not interested in fashion, are nevertheless wearing clothes as directed by fashion in one way or another" (Wilson, "Fashion and Memory"). Moreover the drive to adorn ourselves in certain clothes (jeans, dresses, sweat suits, etc.) stems not from simply abiding by decorum but also insists on personality and personal history. By stressing the relationship between fashion and memory is almost, if not wholly, tautological yet as Wilson points out it is easy to dismiss fashion's unique influence on both the mind and body.

While the Hanae Mori dress I found in a second hand store may represent what Angela McRobbie has identified as part of the "current vogue for nostalgia [...] a way of bringing history into an otherwise ahistorical present" (1989, 23), the dress also becomes a signifier for both my sense of fashion and the memories it has and will further translate. Its position in my closet, therefore, occupies a special sartorial space in my personal archive.

\section{REFERENCES}

Entwistle, Joanne., and Elizabeth Wilson. Body Dressing. Oxford ; New York: Berg, 2001.Print.

Wilson, Elizabeth. "Fashion \& Memory: Unravelling twentieth-century fashion's relationship with memory and perpetual pursuit of the new." Vestoj: The Platform for Critical Thinking on Fashion. Web. 16 May, 2016.

McRobbie, Angela. "Second-Hand Dresses and the Role of the Rag Market." Zoot Suits and SecondHand Dresses: An Anthology of Fashion and Music. New York: Routledge, 1989. Print. 
TranscUlturAl, vol. 8.1 (2016), 177-178.

http://ejournals.library.ualberta.ca/index.php/TC

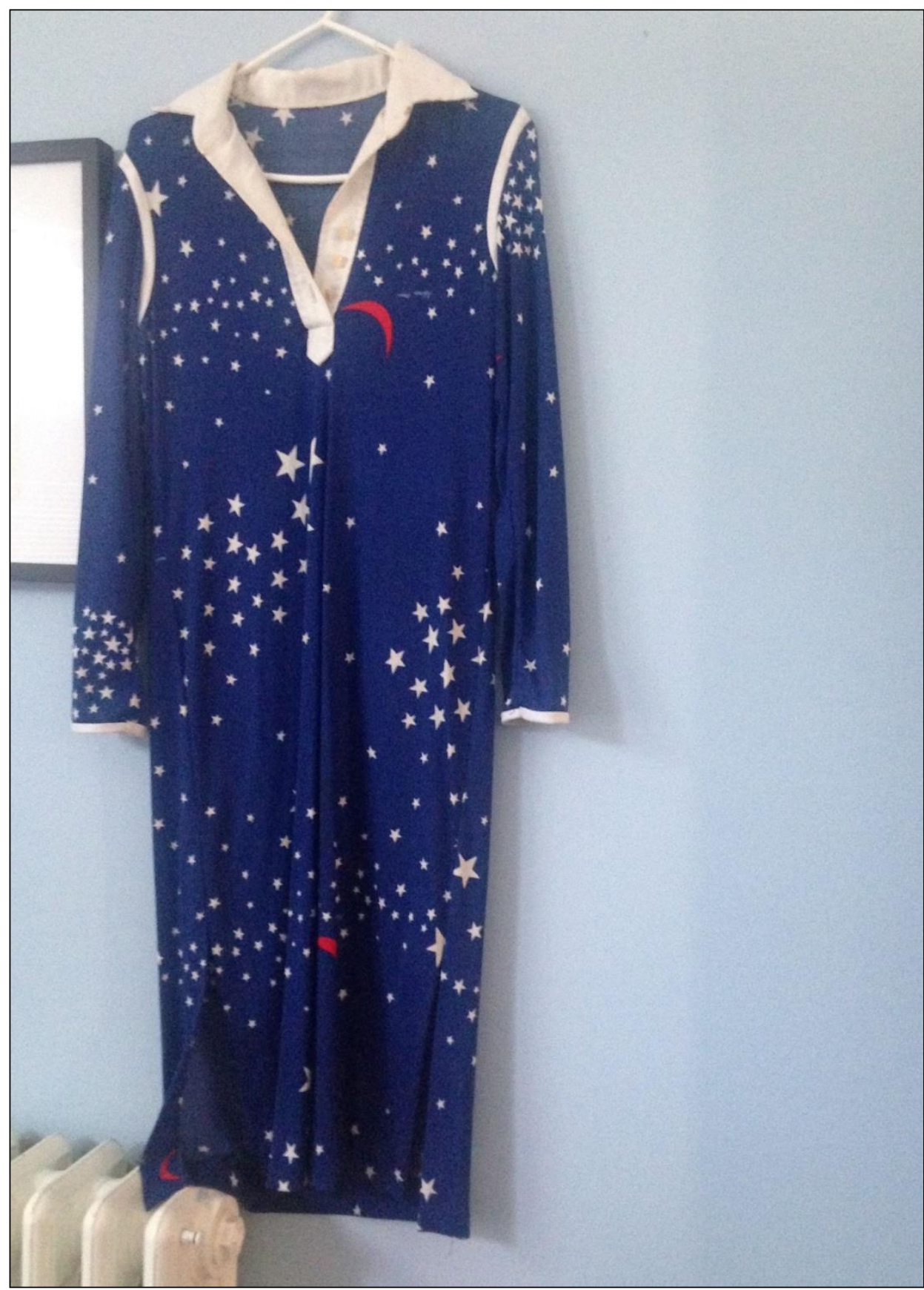

Photo credit: Kathryn Franklin 